\title{
STUDY ON THE GLUTATHIONE METABOLISM OF THE FILAMENTOUS FUNGUS ASPERGILLUS NIDULANS
}

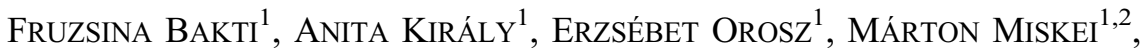 \\ TAMÁS EMRI ${ }^{1}$, ÉVA LEITER $^{1 *}$ and ISTVÁN PÓCSI ${ }^{1}$ \\ ${ }^{1}$ Department of Biotechnology and Microbiology, Faculty of Science and Technology, \\ University of Debrecen, Debrecen, Hungary \\ ${ }^{2}$ MTA-DE Momentum, Laboratory of Protein Dynamics, Department of Biochemistry and \\ Molecular Biology, University of Debrecen, Debrecen, Hungary
}

(Received: 22 July 2016; accepted: 23 November 2016)

\begin{abstract}
Yeast protein sequence-based homology search for glutathione (GSH) metabolic enzymes and GSH transporters demonstrated that Aspergillus nidulans has a robust GSH uptake and metabolic system with several paralogous genes. In wet laboratory experiments, two key genes of GSH metabolism, $g \operatorname{cs} A$, and $g l r A$, encoding $\gamma$-L-glutamyl-L-cysteine synthetase and glutathione reductase, respectively, were deleted. The gene $g c s A$ was essential, and the $\Delta g \operatorname{cs} A$ mutant required GSH supplementation at considerably higher concentration than the Saccharomyces cerevisiae gsh 1 mutant $\left(8-10 \mathrm{mmol}^{-1}\right.$ vs. $\left.0.5 \mu \mathrm{mol} \mathrm{l}^{-1}\right)$. In addition to some functions known previously, both genes were important in the germination of conidiospores, and both gene deletion strains required the addition of extra GSH to reach wild-type germination rates in liquid cultures. Nevertheless, the supplementation of cultures with $10 \mathrm{mmol} \mathrm{l}^{-1} \mathrm{GSH}$ was toxic for the control and $\Delta g l r A$ strains especially during vegetative growth, which should be considered in future development of high GSHproducer fungal strains. Importantly, the $\Delta g l r A$ strain was characterized by increased sensitivity toward a wide spectrum of osmotic, cell wall integrity and antimycotic stress conditions in addition to previously reported temperature and oxidative stress sensitivities. These novel phenotypes underline the distinguished functions of GSH and GSH metabolic enzymes in the stress responses of fungi.
\end{abstract}

Keywords: glutathione, glutathione metabolism, environmental stress, in silico analysis, Aspergillus nidulans

*Corresponding author; E-mail: leiter.eva@science.unideb.hu 


\section{Introduction}

Glutathione ( $\gamma$-L-glutamyl-L-cysteinyl-glycine, GSH) is the most abundant thiol in aerobic prokaryotic and eukaryotic organisms, which plays essential roles in many biological processes, e.g., in the defense against harmful xenobiotics, heavy metals, and reactive oxygen species as well as in the redox stabilization of membranes, membranous cellular structures like mitochondria and the nuclei $[1,2]$. GSH also fulfills important redox-independent functions like in the maturation of iron-sulfur clusters $[3,4]$ and also serves as an important nitrogen and sulfur reserve under starvation [1].

The synthesis of GSH is catalyzed in two consecutive steps by $\gamma$-L-glutamyl-L-cysteine synthetase ( $\gamma$-GCS, or glutamate-cysteine ligase) and glutathione synthetase [1, 5]. In the baker's yeast Saccharomyces cerevisiae, the disruption of $\gamma$-GCS resulted in GSH auxotrophy [6], which could be rescued by dithiothreitol, cysteine, $\beta$-mercaptoethanol, and N-acetylcysteine [7, 8]. $\gamma$-GCS deficiency also results in severe clinical symptoms in humans including hemolytic anemia [9].

Besides de novo biosynthesis, the regeneration of GSH from its oxidized form glutathione disulfide (GSSG) by the NADPH-consuming enzyme glutathione reductase (GR) is also of pivotal importance in the stabilization of the GSH/GSSG redox balance within the cells [1,5]. In S. cerevisiae, the GR-encoding gene GLRI is not essential [10] but it is a key element of the oxidative stress defense system of yeast [7]. Importantly, the GR-encoding gene $p g r l$ was essential in the fission yeast Schizosaccharomyces pombe to maintain growth and spore viability [11]. Although the deletion of glrA coding for GR in Aspergillus nidulans resulted in a temperaturesensitive phenotype it was not essential [12] and, hence, the overall view on the role of GR in A. nidulans was more budding yeast-like than fission yeast-like. It is noteworthy that reductions in growth, oxidative stress defense, and cephalosporin $\mathrm{C}$ production caused by the disruption of the GR-encoding gene could be reversed by the addition of exogenous methionine [13].

Although the anabolic and catabolic pathways as well as the transport processes influencing intracellular GSH concentrations are well understood $[1,5,14]$, future studies may shed light on the fine-tuning of cellular (and sub-cellular) redox control by GSH and also on further, not-yet-known biosynthetic, physiological, and developmental functions attributable to this sulfurcontaining tripeptide $[1,3,4]$. For example, more recent studies demonstrated the involvement of GSH in the biosynthesis of the important Aspergillus fumigatus virulence factor gliotoxin [15].

Hence, to gain a deeper insight in the importance and functions of GSH in the stress defense and development of A. nidulans, we deleted the genes glrA and 
gcs $A$ in this filamentous fungus model organism and phenotypically characterized the $\Delta g \operatorname{cs} A$ and $\Delta g \operatorname{lr} A$ strains. In this study, we collected and discussed new data on the important roles played by GcsA and GlrA in supporting germination of conidiospores and also in the defense against various types of environmental stress, e.g., hyperosmotic stress, cell wall integrity stress and exposures to antimycotics. The foreseeable biomedical and industrial significances of the new observations are also discussed in this paper.

\section{Materials and Methods}

In silico reconstruction of GSH metabolic pathways and identification of putative GSH transporters in A. nidulans

Putative elements of the GSH metabolic pathways as well as presumptive GSH transporters were identified in A. nidulans by extracting information from the Aspergillus Genome Database (AspGD, http://www.aspgd.org/) and by homology search following the protocols previously described by Miskei et al. [16]. Concisely, homology search was carried out with the sequences of $S$. cerevisiae GSH metabolic proteins and GSH transporters (downloaded from the Saccharomyces Genome Database, SGD, http://www.yeastgenome.org/) using the BLASTP search program in AspGD. Following that another round of BLAST homology search was carried out in SGD using the sequences of the candidate $A$. nidulans proteins. If the highest homology yeast protein was identical to that we started the homology search with the $A$. nidulans protein was regarded as part of the GSH metabolism and transport of the fungus and was discussed [16].

Strains, culture media, and production of conidia

The following strains were used in our study: rJMP1.59 (pyrG89; pyroA4; $v e A^{+}$), rRAW16 (pyrG89; yA2; veA $A^{+}$), THS30.3 [17], $\Delta g l r A$ (pyrG89; $\operatorname{sglrA::}$ AfupyrG $\left.{ }^{+} ; v^{2} A^{+}\right)$, and $\Delta g c s A\left(\operatorname{pyrG89} ; \Delta g c s A:: A f u p y r G^{+} ; v e A^{+}\right)$. For cultivation of the $A$. nidulans strains, minimal nitrate medium (MNM) was used with appropriate nutritional supplements [18]. The GSH supplementations of the $\Delta g l r A$ and the $\Delta g c s A$ mutants were optimized (Supplementary Figure S1) and, as a result, culture media (both MNM agar plates and MNM liquid media) were supplemented with $10 \mathrm{mmol} \mathrm{l}^{-1} \mathrm{GSH}$ unless otherwise indicated, which was in line with the protocol of Sato et al. [12]. Conidiospores were also produced usually on MNM agar supplemented with $10 \mathrm{mmol}^{-1} \mathrm{GSH}$, and these sporulation cultures were 
incubated at $37^{\circ} \mathrm{C}$ for 6 days [19]. All cultures were supplemented with GSH dissolved in sterile distilled water at temperatures lower than $50{ }^{\circ} \mathrm{C}$.

\section{Construction of the $\Delta g l r A$ and $\Delta g c s A$ gene deletion strains}

Two genes encoding key players in the maintenance of the intracellular GSH concentration and the GSH/GSSG redox balance, glrA (encoding GR, locus ID: AN0932, AspGD; [12]) and gcsA (coding for $\gamma$-GCS, locus ID: AN3150, AspGD), were deleted by the DJ-PCR method of Yu et al. [20] using the primers listed in Supplementary Table S-I $[18,20]$. The amplified deletion cassettes were used to transform RJMP1.59 strain using the Vinoflow FCE lysing enzyme [21]. Single copy transformants were selected after Southern blot analysis and crossed with rRAW16 to get prototrophic strains. All progenies of the independent crosses proved to be single-copy deleted mutants by Southern analyses.

Growth studies with the $\Delta g c s A$ strain on MNM agar plates in the presence of various nutritional supplements

A series of MNM agar growth assays were carried out to screen for possible nutritional supplement(s) complementing GSH auxotrophy in the $\Delta \operatorname{gcs} A$ mutant. The following supplements were added at the concentrations indicated: $24 \mathrm{mmol} 1^{-1}$ Na-glutamate (Na-Glu), $4 \mathrm{mmol} \mathrm{l}^{-1}$ cysteine (Cys), $20 \mathrm{mmol} \mathrm{l}^{-1}$ glycine (Gly), $20 \mathrm{mmol} \mathrm{l}^{-1}$ methionine (Met), $24 \mathrm{mmol} \mathrm{l}^{-1} \mathrm{Na}-\mathrm{Glu}+4 \mathrm{mmol}^{-1} \mathrm{Cys}+20 \mathrm{mmol} \mathrm{l}^{-1}$ Gly, $24 \mathrm{mmol} \mathrm{l}^{-1} \mathrm{Na}-\mathrm{Glu}+20 \mathrm{mmol} \mathrm{l}^{-1} \mathrm{Met}+20 \mathrm{mmol} \mathrm{l}^{-1} \mathrm{Gly}, 0.5 \%$ yeast extract, and $2.0 \%\left(58 \mathrm{mmol}^{-1}\right)$ lactose [15, 22]. In these assays, agar plates were point-inoculated by pipetting $10^{5}$ freshly grown (6 days) conidia suspended in $5 \mu \mathrm{l}$ aliquots of $0.9 \% \mathrm{NaCl}, 0.01 \%$ Tween 80 solution onto MNM agar plates, and were incubated for 5 days at $37^{\circ} \mathrm{C}$ [19].

\section{Determination of germination rates in submerged liquid cultures}

To determine germination rates, $10^{8}$ freshly grown conidia were inoculated into $100 \mathrm{ml}$ MNM without any nutritional supplements, or supplemented with $10 \mathrm{mmol} \mathrm{l}^{-1} \mathrm{GSH}$ or the mixture of $20 \mathrm{mmol} \mathrm{l}^{-1}$ Met, $20 \mathrm{mmol} \mathrm{l}^{-1}$ Gly, and $4 \mathrm{mmol} \mathrm{l}^{-1} \mathrm{Na}-\mathrm{Glu}$ as required. All submerged cultures were grown at $37^{\circ} \mathrm{C}$ with shaking at $3.3 \mathrm{~Hz}$ frequency for 6,10 , and $24 \mathrm{~h}$ incubation times [19]. Germination rates (number of germinated spores/total number of spores) were determined via counting conidia and also germinated conidia under a phase contrast microscope (Euromex, Arnhem, The Netherlands). 
Production of reactive species (RS) and determination of specific intracellular enzyme activities

In these experiments, the strains were sporulated either on GSH-free MNM agar (the THS30.3 control strain) or on MNM agar supplemented with $10 \mathrm{mmol} \mathrm{l}^{-1}$ GSH as required (all tested strains including the THS30.3 control strain). Following that all strains were pre-cultured in $100 \mathrm{ml}$ aliquots of MNM with (the THS30.3 control and both the $\Delta g l r A$ and $\Delta g c s A$ gene deletion strains) or without (only the THS30.3 control strain) $10 \mathrm{mmol}^{-1} \mathrm{GSH}$ supplementation. All culture media were inoculated and incubated as described above for $20 \mathrm{~h}$. Mycelia were always harvested (filtered and washed on sintered glass) and were transferred to $100 \mathrm{ml}$ aliquots of freshly prepared MNM without any GSH supplementation. The intracellular RS levels were characterized by the formation of $2^{\prime}, 7^{\prime}$-dichlorofluorescein (DCF) from 2',7'-dichlorofluorescin diacetate according to Yin et al. [23]. Changes in the specific activities of antioxidant enzymes were also recorded in separate experiments as described before by Emri et al. [24].

Stress sensitivity studies

To study the stress sensitivity of the $\Delta g l r A$ mutant, the agar plate assays of Balázs et al. [19] were adapted with small modifications. The following stressgenerating agents were tested: hyperosmotic stress: $1.0 \mathrm{~mol}^{-1} \mathrm{KCl}, 1.0 \mathrm{~mol}^{-1} \mathrm{NaCl}$, $2.0 \mathrm{~mol}^{-1}$ sorbitol; cell wall integrity stress: $54 \mu \mathrm{mol} \mathrm{l}^{-1}$ Congo Red; antimycotic stress: $200 \mu \mathrm{g} \mathrm{ml}^{-1}$ fluconazole and $75 \mu \mathrm{g} \mathrm{m}{ }^{-1}$ amphotericin B. Stress plates were also point-inoculated with $10^{5}$ conidia and were incubated at $30^{\circ} \mathrm{C}$ for 5 days $[19,23]$.

\section{Statistical analysis of experimental data}

All experiments were performed in three independent sets, and mean \pm SD values were calculated and are presented. Statistical significances were calculated using Student's $t$-test, and $p$-values less than 0.05 were considered as statistically significant.

\section{Results}

GSH metabolic enzymes and GSH transporters in A. nidulans

As summarized in Figure 1 and Supplementary Table S-II, all elements of GSH metabolism and GSH transport, which are well-characterized in budding 


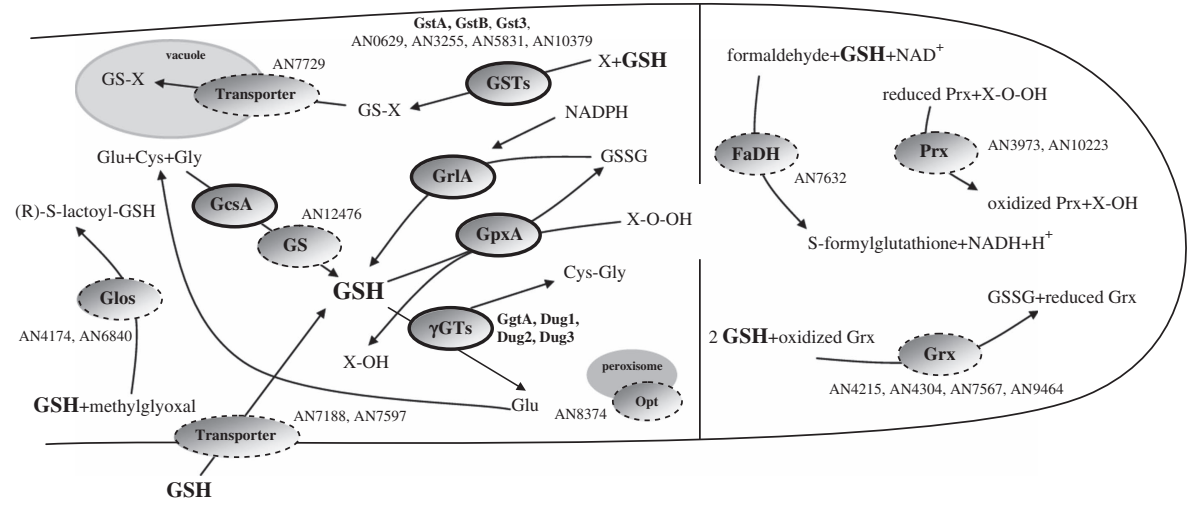

Figure 1. A schematic model of GSH metabolism in A. nidulans. Locus IDs were exported from the AspGD (http://www.aspergillusgenome.org/). Note that enzymes marked with dashed lines have not been characterized yet in A. nidulans. For further details, see Supplementary Table S-II

yeast [1], are also present in A. nidulans. These proteins are associated with the biosynthesis and degradation of GSH, the maintenance of redox balance within the cells, the detoxification of toxic endogenous and exogenous metabolites as well as the uptake and intracellular transport of GSH (Figure 1, Supplementary Table S-II; [1]). Importantly, this filamentous fungus seems to possess two putative homologs of the following $S$. cerevisiae proteins: Prx1 peroxiredoxin (AN3973, AN10223), Ure2 glutathione peroxidase/glutathione S-transferase (GPx/GST; AN3255, AN4905/GstA), and Opt1 cell surface GSH transporter (AN7597, AN7188).

\section{Optimization of the GSH supplementation of the $\Delta g \operatorname{lr} A$ and $\Delta g c s A$ mutant strains}

Both strains required GSH supplementation when they were grown on MNM agar at $37^{\circ} \mathrm{C}$ for 5 days, and optimal growths were recorded at $8-10 \mathrm{mmol} 1^{-1} \mathrm{GSH}$ concentrations in both cases (Supplementary Figure S1). It is worth noting that the temperature sensitivity of the $\Delta g \operatorname{lr} A$ strain observable at $37{ }^{\circ} \mathrm{C}$ [12] was fully complemented by the addition of $10 \mathrm{mmol}^{-1} \mathrm{GSH}$. Nevertheless, the supplementation of MNM agar with $8-10 \mathrm{mmol}^{-1} \mathrm{GSH}$ still resulted in a high but still partial (75\%-80\%) complementation of the no growth phenotype of the $\Delta$ gcs $A$ strain, which was observed at lower GSH concentrations (Supplementary Figure S1).

Growth of the $\Delta g c s A$ strain on MNM agar supplemented with various nutrients

As shown in Supplementary Figure S2, the GSH auxotrophy of the $\Delta g \operatorname{cs} A$ mutant could not be complemented with any nutritional supplements tested 
including yeast extract, lactose, or the amino acids Na-Glu, Gly, Cys, Met, and their combinations.

\section{Germination of the conidiospores of the $\Delta g \operatorname{lr} A$ and $\Delta g \operatorname{cs} A$ mutants}

As expected, both mutants germinated well in GSH supplemented MNM culture medium (Figure 2). The $\Delta g l r A$ mutant also germinated in MNM medium supplemented with $20 \mathrm{mmol}^{-1} \mathrm{Met}, 20 \mathrm{mmol}^{-1} \mathrm{Gly}$, and $24 \mathrm{mmol}^{-1} \mathrm{Na}-\mathrm{Glu}$ instead of GSH owing to de novo GSH biosynthesis. Not surprisingly, the germination rates of both mutant strains were rather low in the absence of GSH ( $10.7 \%$ for the $\Delta g \operatorname{lr} A$ and $8.1 \%$ for the $\Delta g \operatorname{cs} A$ strains) because these spores could only rely on their intracellular GSH reserves, and the $\Delta g \operatorname{cs} A$ mutant was not able to use the combination of the amino acids Met, Gly, and Glu for de novo GSH

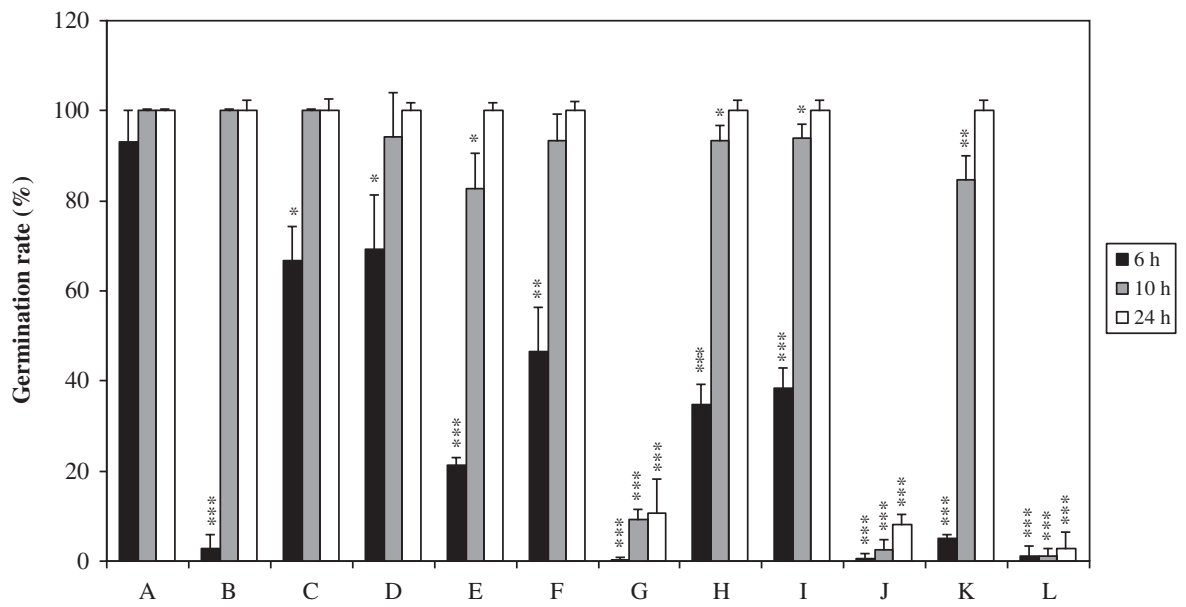

Figure 2. Germination rates of conidiospores produced by the control THS30.3 and the gene deletion mutant $\Delta g l r A$ and $\Delta g c s A$ strains under various culture conditions. Freshly grown (harvested after 6 days incubation) conidia $\left(10^{8}\right.$ spores in each experiment) were inoculated into $100 \mathrm{ml}$ aliquots of MNM, and the submerged cultures were grown at $37^{\circ} \mathrm{C}$ and at $3.7 \mathrm{~Hz}$ shaking frequency for 6,10 , and

24 h. In Parts A-C, the THS30.3 control strain was sporulated on MNM without any GSH supplementation. In all other cases (the THS30.3 control strain in Parts D-F, the $\Delta g l r A$ strain in Parts G-I and the $\Delta g c s A$ strain in Parts J-L), conidiospores were produced on MNM supplemented with $10 \mathrm{mmol}^{-1} \mathrm{GSH}$. Conidia were inoculated into one of the following culture media: MNM (Parts A, D, $\mathrm{G}$, and J), MNM supplemented with $10 \mathrm{mmol}^{-1} \mathrm{GSH}$ (Parts B, E, H, and K), and MNM supplemented with $20 \mathrm{mmol} \mathrm{l}^{-1}$ methionine, $20 \mathrm{mmol}^{-1}$ glycine, and $24 \mathrm{mmol} \mathrm{l}^{-1} \mathrm{Na}$-glutamate (Parts $\mathrm{C}, \mathrm{F}, \mathrm{G}$, and L). Note that the germination rates reached $100 \%$ after $24 \mathrm{~h}$ incubation in all cases with the exception of Parts $\mathrm{G}, \mathrm{J}$, and L. In this figure, mean $\pm \mathrm{SD}$ values calculated from three independent experiments are presented. Asterisks indicate significant differences in comparison to the appropriate controls (Part A) at $p<5 \%(*), p<1 \%(* *)$, and $p<0.1 \%(* * *)$ as calculated by the Student's $t$-test 
synthesis either (Figure 2). Importantly, the addition of $10 \mathrm{mmol}^{-1} \mathrm{GSH}$ to MNM hindered considerably the germination of THS30.3 conidia ( $6 \mathrm{~h}$ incubation time; Part D in Figure 2) when the control strain was sporulated on GSH-free MNM agar. In addition, when conidia of the control strain were produced on GSHsupplemented MNM agar the sporulation rates measured in GSH-free or in Met-Gly-Glu supplemented MNM media (Parts D and F in Figure 2) were significantly lower than those found in the appropriate controls, where THS30.3 conidia were produced on GSH-free MNM agar (Parts A and C in Figure 2).

\section{$R S$ productions and GSH-dependent and GSH-independent antioxidant enzyme activities}

To characterize the nature of stress sensed by $A$. nidulans cells pre-cultured in the presence of $10 \mathrm{mmol}^{-1} \mathrm{GSH}$ and transferred to GSH-free MNM in liquid cultures, increases in DCM, changes in RS levels (given by specific DCF productions) as well as alterations in the specific activities of some antioxidative enzymes were measured at 6 and $12 \mathrm{~h}$ incubation times (Table I).

Unexpectedly, the growth of the THS30.3 control strain was almost completely inhibited during pre-culturing in MNM supplemented with $10 \mathrm{mmol} \mathrm{l}^{-1} \mathrm{GSH}$ (Table I). When the physiological conditions of THS30.3 control cultures precultured in the presence and absence of GSH were compared, mycelia from the GSH-supplemented cultures possessed decreased specific GPx and GR activities (3.9 times and 2.6 times lower, respectively) with remarkably high (about 100 times higher) RS levels although the specific catalase activity was about eleven times higher (Table I). After $12 \mathrm{~h}$ incubation in GSH-free MNM, biomass gains by the GSH pre-cultured control were approximately 7-fold with improving physiological parameters and recovery from oxidative stress (e.g., RS levels decreased 150 -fold concomitantly with a 6.5 -fold increase in the specific GPx activity). Meanwhile there were no significant differences left in specific RS productions and GPx activities of the GSH-MNM and MNM pre-cultured mycelia the differences between the specific GR and catalase activities remained still high, approximately 3.7 times lower and 7.8 times higher for the GSH pre-cultured mycelia, respectively (Table I).

As far as the gene deletion mutants are concerned, the $\Delta g l r A$ and $\Delta g c s A$ strains grew considerably better in the presence of $10 \mathrm{mmol}^{-1}$ GSH than the GSH pre-cultured THS30.3 control strain (Table I). Nevertheless, the mycelia of the $\Delta g l r A$ mutant with no GR activity accumulated 2.5 times more RS than those of the $\Delta g \operatorname{cs} A$ strain although the specific catalase activity in the $\Delta g l r A$ strain was 3.8 times higher (Table I). Importantly, the oxidative stress was completely 


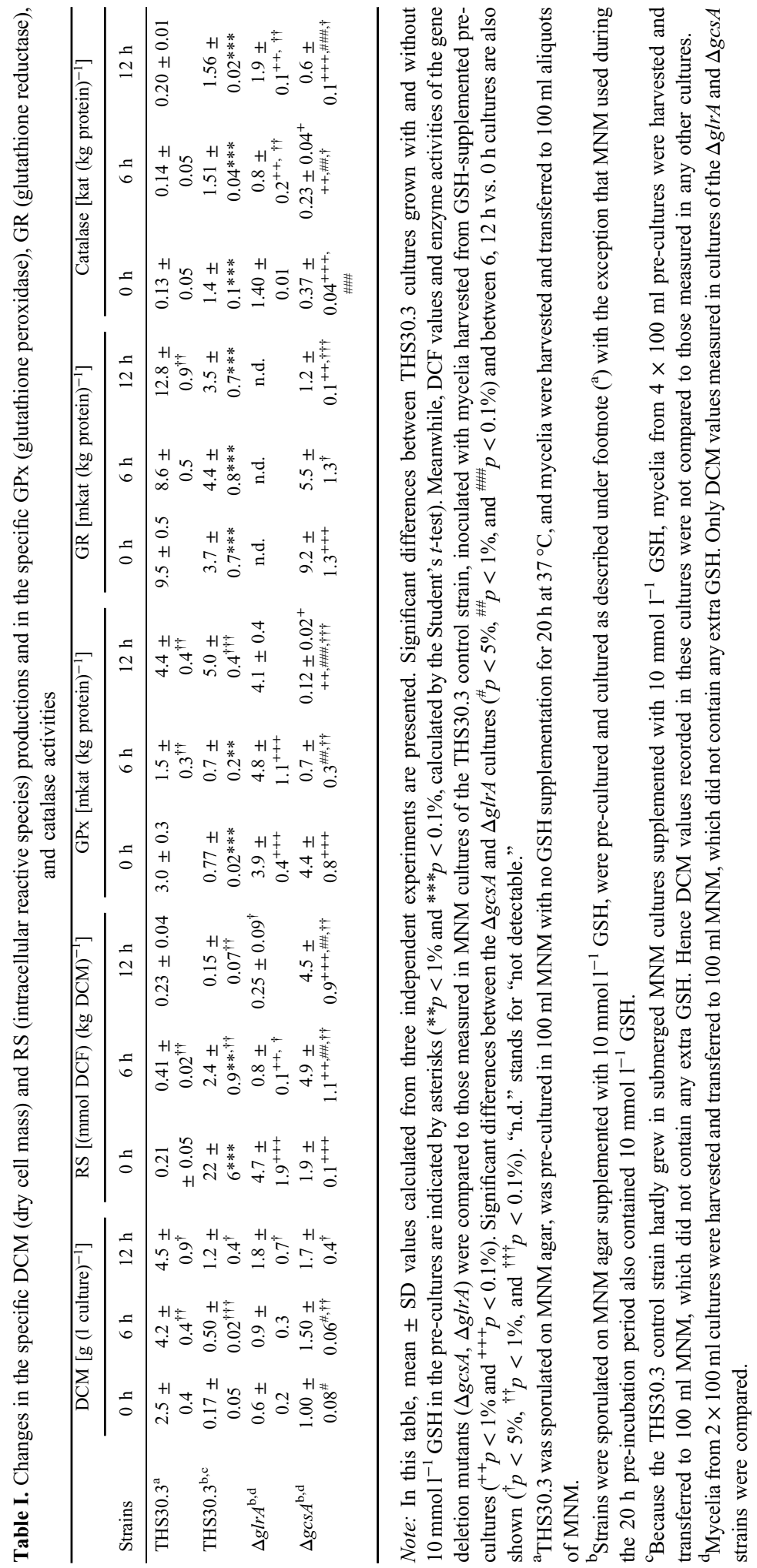


eliminated in the $\Delta g l r A$ cultures after $12 \mathrm{~h}$ incubation in the absence of GSH (RS production decreased 18.8-fold) similar to the THS30.3 control strain. Meanwhile an accumulating oxidative stress was clearly observable in the $\Delta g \operatorname{cs} A$ cultures with increased RS productions (a 2.4-fold increase between 0 and $12 \mathrm{~h}$ incubation times) and specific catalase activities (increased 1.35-fold) as well as with significantly decreased specific GPx and GR activities (decreased 36.7-fold and 7.7-fold, respectively) (Table I).

Stress sensitivity phenotypes of the $\Delta$ glrA mutant

Temperature sensitivity and oxidative sensitivity phenotypes of a $\Delta g l r A$ gene deletion mutant have been reported before by Sato et al. [12]. The $\Delta g \operatorname{lr} A$ mutant constructed and characterized in this study by us also showed increased temperature and oxidative stress sensitivities similar to those described previously (data not shown; [12]). In addition, we also demonstrated for the first time the increased hyperosmotic stress $\left(1.0 \mathrm{~mol}^{-1} \mathrm{KCl}, 1.0 \mathrm{~mol} \mathrm{l}^{-1} \mathrm{NaCl}\right.$, and $2.0 \mathrm{~mol}^{-1}$ sorbitol), cell wall integrity stress ( $54 \mu \mathrm{mol} 1^{-1}$ Congo Red) and antimycotic (200 $\mu \mathrm{g} \mathrm{ml}^{-1}$ fluconazole and $75 \mu \mathrm{g} \mathrm{ml}^{-1}$ amphotericin B) sensitivity of the $\Delta \mathrm{glr} A$ strain (Figure 3).

\section{Discussion}

GSH possesses a number of redox-dependent and redox-independent functions in eukaryotic organisms including fungi $[1,3,4]$. It is important to note that the elucidation of the remarkably versatile physiological functions of GSH needs further research. In this study, we primarily aimed at screening for new GSHmetabolism-related phenotypes especially concerning conidiospore germination and also for GSH-dependent stress defenses. Any new information on the physiological and developmental functions of GSH and GSH metabolic enzymes in fungi may help us to gain a deeper insight in the pathogeneses of human pathogenic fungi [15], to set up new antifungal drug development strategies $[25,26]$ and also to develop new GSH overproducer [27-29] as well as more stress tolerant and more stable $[1,2,17,30]$ industrial fungal strains.

\section{A. nidulans possesses a robust GSH uptake and GSH metabolic system}

The aspergilli, which represent an outstandingly important group of filamentous fungi, have a complex and robust stress response system, which is 

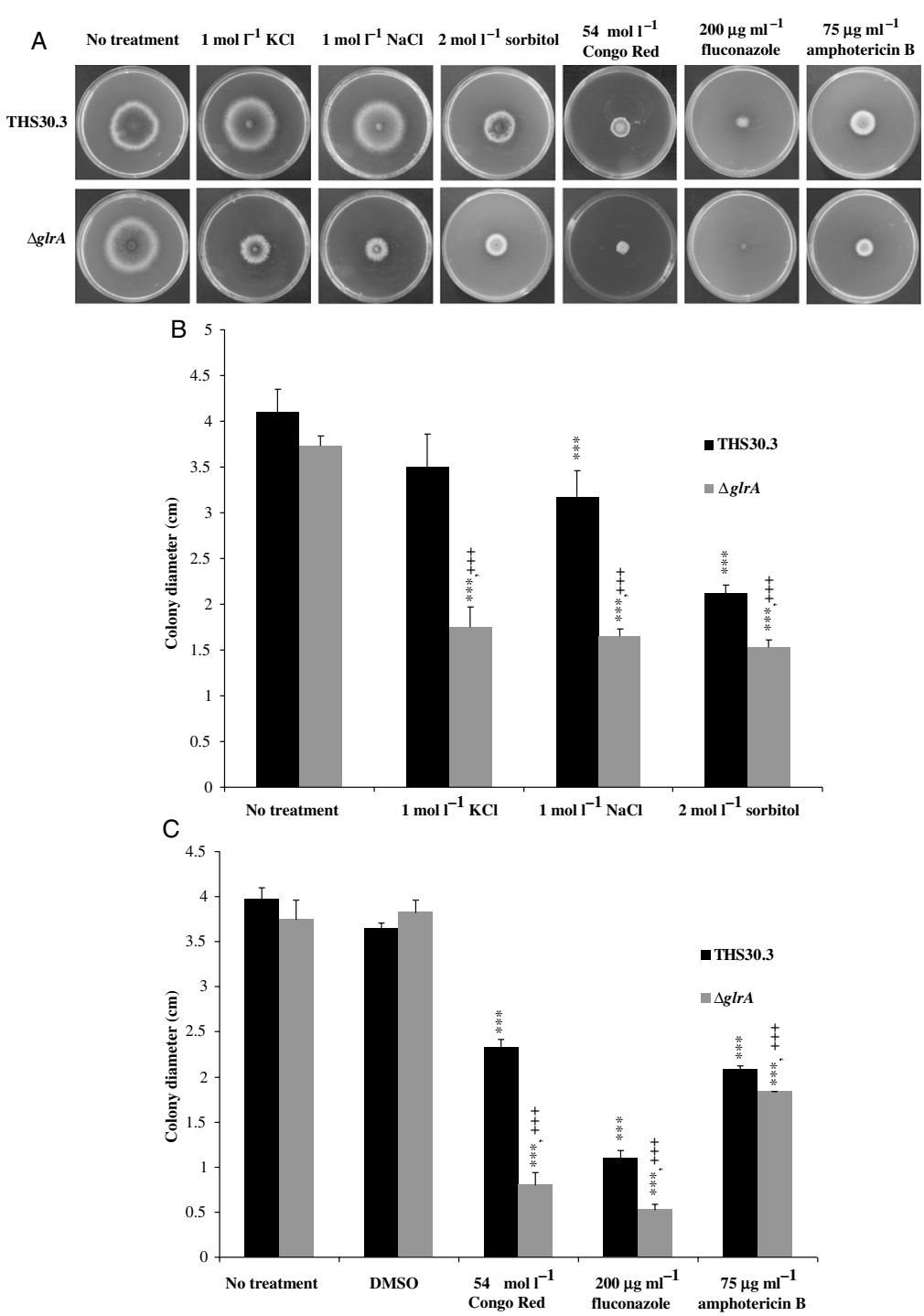

Figure 3. Stress sensitivities of the THS30.3 control and the $\Delta g l r A$ gene deletion mutant strains exposed to various types of stress. (A) Typical stress sensitivities observed in surface cultures on MNM agar plates are shown. (B) and (C) Mean colony diameters of the control (black columns) and the mutant (gray columns) strains are presented with SD values calculated from three independent experiments. In Part B, cultures were exposed to ionic $(\mathrm{NaCl}$ and $\mathrm{KCl}$ ) and non-ionic (sorbitol) hyperosmotic stress, meanwhile in Part $\mathrm{C}$, growth inhibitions caused by cell wall integrity stress (Congo Red) and antimycotics (fluconazole and amphotericin B) are shown. Conidiospores ( $10^{5}$ in $5 \mu \mathrm{l}$ suspension) were point-inoculated on MNM agar and the agar plates were incubated for 5 days. Since growth of $\Delta g l r A$ was comparable to the control strain without GSH supplementation at $30{ }^{\circ} \mathrm{C}$, all plates were incubated at this temperature. Because amphotericin B was dissolved and added in DMSO, suitable controls for this antifungal were always prepared. The concentration of DMSO in these MNM agar plates was $2 \%(\mathrm{v} / \mathrm{v})$. Asterisks and plus symbols indicate significant differences in comparison to non-treated controls (treated THS30.3 vs. non-treated THS30.3 and treated $\Delta g \operatorname{lr} A$ vs. non-treated $\Delta g l r A$ ) and to treated control strain (treated $\Delta g l r A$ vs. treated THS30.3), respectively,

at $p<0.1 \%(* * *,+++) . p$ values were calculated using the Student's $t$-test 
suitable to cope with a wide spectrum of environmental stress [23]. In good accordance with this, some genes encoding important GSH metabolic enzymes in $S$. cerevisiae like Prx1 mitochondrial peroxiredoxin (possessing thioredoxin peroxidase activity and its regeneration requires thioredoxin reductase and GSH in yeast [22]) and Ure2 protein with GPx activity (but also can mutate to gain GST activity [31]) as well as Opt1 cell surface GSH transporter (also known as Gsh11 or Hgt1 [32]) each brought up two paralogs in A. nidulans (Figure 1, Supplementary Table S-II).

Although $A$. nidulans is a widely used filamentous fungus model organism with its whole genome sequenced and annotated [33] the number of functionally characterized proteins related to GSH metabolism and transport is surprisingly low (Figure 1, Supplementary Table S-II). For example, the GlrA enzyme with GR activity plays an important role in the oxidative stress defense system of the fungus [12] and also in the reduction of cytotoxic elemental sulfur [34]. Interestingly, meanwhile GstA and GstB GSTs take part in the degradation of various toxic xenobiotics [19,34] and even in the detoxification of metals (GstA, [35]), GgtA $\gamma$-glutamyl transpeptidase is not necessary for the bulk degradation of GSH [36]. Instead, the DUG pathway relying on Dug 1-3 proteins is likely to be responsible for the cytosolic degradation of GSH [34]. It is worth mentioning that some genes coding for important GSH metabolism-related enzymes have only been characterized through transcriptional (dug1-3 [36]; gpxA [37]) or translational (gst3 [38]) changes. Therefore, a deeper characterization of GSH metabolic enzymes and GSH transporters (Figure 1, Supplementary Table S-I) using molecular genetic tools are urgently needed in A. nidulans.

\section{A. nidulans needs high concentration of GSH for growth and germination of conidia}

In this study, the deletion of gcs $A$ encoding $\gamma$-GCS resulted in a lethal phenotype unless culture medium was supplemented with exogenous GSH similarly to previous observations with the $\triangle G S H 1$ mutant of $S$. cerevisiae [6-8]. Unlike in the case of budding yeast [7, 8], the $\Delta g c s A$ mutant required exogenous GSH at much higher concentration (at $8-10 \mathrm{mmol}^{-1}$ at least) than GSH-depleted $S$. cerevisiae $\Delta g s h 1$ cells $\left(0.5 \mu \mathrm{mol}^{-1}\right.$ [8]). These findings indicate that GSH may possess further crucially important physiological functions in A. nidulans other than the stabilization of the redox milieu of the fungal cells $[7,8]$. The essential redox-independent functions of GSH, e.g., in the maturation of ironsulfur clusters, have been summarized more recently by several authors [3, 4]. Of course, we cannot underestimate the significance of the versatile redox-dependent 
functions played by GSH either, e.g., in the stabilization of various cellular membranous structures [1-3]. It is remarkable that other attempts to rescue the growth of $\gamma$-GCS-deficient $A$. nidulans cells e.g., by sulfur-containing amino acids like Cys or Met and by their combinations with Na-Glu and Gly, or by the addition of yeast extract or lactose (a carbon source, which stimulates GSH-synthesis in Penicillium chrysogenum [24]) also failed in this filamentous fungus. These observations shed light on the minimal GSH requirements of filamentous fungi, which seem to well exceed those of saccharomycetes yeasts $[7,8]$.

The maturation, survival during storage, stress tolerance, and germination of conidiospores highly depend on the availability of antioxidants like catalase [39], mannitol [40], GSH [41], and also osmolytes like trehalose [42]. The remarkable importance of GSH in germination of $A$. nidulans conidiospores was demonstrated in this study by the decreased germination rates of the $\Delta g \operatorname{lr} A$ and $\Delta g \operatorname{cs} A$ strains, although the GR deficient mutant was able to re-synthesize GSH effectively from the combined amino acids of Na-Glu+Met+Gly (Figure 2). Any disturbances of the GSH metabolic system of the aspergilli seem therefore suitable tools to control the germination of the asexual spores of these ascomycetous fungi, which include well-known opportunistic fungal parasites of humans like A. fumigatus [43-45].

Overdosing GSH is toxic for A. nidulans

Interestingly, the germination of the THS30.3 control strain was delayed by exogenous GSH added at $10 \mathrm{mmol}^{-1}$ concentration, and the same strain showed decreased germination rate at $6 \mathrm{~h}$ incubation time, when conidiospores produced on GSH-supplemented MNM agar were inoculated into GSH-free or Na-Glu+Met+Gly containing MNM (Figure 2). On the other hand, the same spores germinated better in GSH-supplemented MNM than those which were produced in the absence of exogenously added GSH (Figure 2). These observations together with the findings that the THS30.3 and the $\Delta g l r A$ strains pre-cultured in MNM in the presence of GSH accumulated high concentrations of RS suggested that GSH added at high, $10 \mathrm{mmol}^{-1}$ concentration was toxic for $A$. nidulans cells (Table I). The severe toxicity of GSH on the THS30.3 control strain (almost no gain in biomass after $20 \mathrm{~h}$ incubation at $37^{\circ} \mathrm{C}$ ) was attributed to the profoundly decreased specific activities of GPx and GR. Meanwhile significant increases in the specific GPx and catalase activities helped $A$. nidulans THS30.3 and $\Delta g \operatorname{lr} A$ strains, respectively, to eliminate residual oxidative stress fast after transferring mycelia to GSH-free MNM (Table I). In the $\Delta g l r A$ strain, the reduction of GSSG by the thioredoxin-thioredoxin reductase-NADPH system [12, 39] may also contribute to the neutralization of RS. Increases in the specific catalase, thioredoxin reductase 
and cytochrome peroxidase activities in the $\Delta g l r A$ strain were regarded as parts of the compensatory mechanisms being set into operation by the deletion of glr $\mathrm{A}$ [12]. All these observations may be valuable in the biotechnologist's point of view when the reduction of the toxic effects of GSH on GSH-overproducer industrial fungal strains [26] is aimed at in future strain development projects.

After transferring $\Delta g \operatorname{cs} A$ mycelia into GSH-free MNM, the depletion of the GSH reserves stimulated RS production with the concomitant decreases in the specific GPx and GR activities (Table I). Under these conditions, compensatory mechanisms like a significant increase in the specific catalase activity could not hinder the onset of oxidative stress in the fungal cells (Table I).

\section{GSH is needed for general stress tolerance in A. nidulans}

GR enzymes regenerate GSH by reducing GSSG at the expense of NADPH $[1,5]$. The elimination of GR-encoding genes resulted in various phenotypes in fungi including reduced growth [13] or even lethality [11], temperature sensitivity [12] as well as decreased oxidative stress [10-13, 46] and sulfur [22] tolerances. Lee et al. [11] reported on the role of GR in the heat and hyperosmotic stress defense systems of $S$. pombe and, in this study, we demonstrated the importance of GlrA in the osmotic, cell wall integrity, and antimycotic stress responses of A. nidulans (Figure 2). It is important to note that a series of tert-butyl hydroperoxide stress tolerant mutants of Candida albicans was developed by Fekete et al. $[47,48]$, and each mutant possessed significantly increased specific GR, GPx, and glucose-6-phosphate dehydrogenase activities. A more recent study by Jakab et al. [49] demonstrated that a selection of these mutants also showed decreased sensitivities to 19 different stress conditions including various types of oxidative, hyperosmotic, heavy metal, cell wall and membrane integrity, unfolded protein response, $\mathrm{pH}$, and thermal (heat and cold) stress. These observations strengthen the view that "altruistic" GSH and GSH metabolic enzymes play a distinguished role in the general stress tolerance of fungi, which is of primary importance when these microorganisms are employed in various bioprocesses $[1,2]$.

\section{Conclusions}

A. nidulans has a robust GSH metabolic and transport system, the elements of which need a thorough functional analysis (Figure 1). GSH itself and GSH metabolic enzymes play a crucially important role in the germination of conidiospores, which observation may be useful when future strategies for the development of new-type antifungals are designed and elaborated. On the other 
hand, any overdose of GSH can be disadvantageous during both spore germination and vegetative growth of hyphae, which should be considered in the development of high-GSH-producer industrial fungal strains. Experimental data collected in this study and also in various fungal species by others have shed light on the remarkable contribution of GSH and GSH metabolic enzymes to the general stress tolerance of fungi, which may be equally interesting for experts working on different fungal growth control and fungal strain development projects.

\section{Acknowledgements}

This work was funded by the Hungarian Scientific Research Fund (project number: OTKA 100464). FB and AK contributed equally to this publication.

\section{Conflict of Interest}

The authors declare no conflict of interest.

\section{References}

1. Pócsi, I., Prade, R. A., Penninckx, M. J.: Glutathione, altruistic metabolite in fungi. Adv Microb Physiol 49, 1-76 (2004).

2. Marí, M., Morales, A., Colell, A., García-Ruiz, C., Kaplowitz, N., Fernández-Checa, J. C.: Mitochondrial glutathione: Features, regulation and role in disease. Biochim Biophys Acta 1830, 3317-3328 (2013).

3. Toledano, M. B., Delaunay-Moisan, A., Outten, C. E., Igbaria, A.: Functions and cellular compartmentation of the thioredoxin and glutathione pathways in yeast. Antioxid Redox Signal 18, 1699-1711 (2013).

4. Kumar, C., Igbaria, A., D’Autreaux, B., Planson, A. G., Junot, C., Godat, E., Bachhawat, A. K., Delanuay-Moisan, A., Toledano, M. B.: Glutathione revisited: A vital function in iron metabolism and ancillary role in thiol-redox control. EMBO J 30, 2044-2056 (2011).

5. Deponte, M.: Glutathione catalysis and the reaction mechanisms of glutathione-dependent enzymes. Biochim Biophys Acta 1830, 3217-3266 (2013).

6. Ohtake, Y., Yabuuchi, S.: Molecular cloning of the $\gamma$-glutamylcysteine synthetase gene of Saccharomyces cerevisiae. Yeast 7, 953-961 (1991).

7. Grant, C. M., Collinson, L. P., Roe, J. H., Dawes, I. W.: Yeast glutathione reductase is required for protection against oxidative stress and is a target gene for yAP-1 transcriptional regulation. Mol Microbiol 21, 171-179 (1996).

8. Spector, D., Labarre, J., Toledano, M. B.: A genetic investigation of the essential role of glutathione: Mutations in the proline biosynthesis pathway are the only suppressors of glutathione auxotrophy in yeast. J Biol Chem 276, 7011-7016 (2001). 
9. Ristoff, E., Larsson, A.: Inborn errors in the metabolism of glutathione. Orphanet J Rare Dis 2, 16 (2007).

10. Muller, E. G.: A glutathione reductase mutant of yeast accumulates high levels of oxidized glutathione and requires thioredoxin for growth. Mol Biol Cell 7, 1805-1813 (1996).

11. Lee, J., Dawes, I. W., Roe, J. H.: Isolation, expression, and regulation of the pgr1(+) gene encoding glutathione reductase absolutely required for the growth of Schizosaccharomyces pombe. J Biol Chem 272, 23042-23049 (1997).

12. Sato, I., Shimizu, M., Hoshino, T., Takaya, N.: The glutathione system of Aspergillus nidulans involves a fungus-specific glutathione S-transferase. J Biol Chem 284, 8042-8053 (2009).

13. Long, L. K., Yang, J., An, Y., Liu, G.: Disruption of a glutathione reductase encoding gene in Acremonium chrysogenum leads to reduction of its growth, cephalosporin production and antioxidative ability which is recovered by exogenous methionine. Fungal Genet Biol 49, 114-122 (2012).

14. Bachhawat, A. K., Thakur, A., Kaur, J., Zulkifli, M.: Glutathione transporters. Biochim Biophys Acta 1830, 3154-3164 (2013).

15. Davis, C., Carberry, S., Schrettl, M., Singh, I., Stephens, J. C., Barry, S. M., Kavanagh, K., Challis, G. L., Brougham, D., Doyle, S.: The role of glutathione S-transferase GliG in gliotoxin biosynthesis in Aspergillus fumigatus. Chem Biol 18, 542-552 (2011).

16. Miskei, M., Karányi, Z., Pócsi, I.: Annotation of stress-response proteins in the aspergilli. Fungal Genet Biol 46, S105-S120 (2009).

17. Emri, T., Szarvas, V., Orosz, E., Antal, K., Park, H., Han, K. H., Yu, J.-H., Emri, T.: Core oxidative stress response in Aspergillus nidulans. BMC Genomics 16, 478 (2015).

18. Leiter, É., Bálint, M., Miskei, M., Orosz, E., Szabó, Z., Pócsi, I.: Stress tolerances of nullmutants of function-unknown genes encoding menadione stress-responsive proteins in Aspergillus nidulans. J Basic Microbiol 56, 827-833 (2016).

19. Balázs, A., Pócsi, I., Hamari, Z., Leiter, É., Emri, T., Miskei, M., Oláh, J., Tóth, V., Hegedűs, N., Prade, R. A., Molnár, M., Pócsi, I.: AtfA bZIP-type transcription factor regulates oxidative and osmotic stress responses in Aspergillus nidulans. Mol Genet Genomics 283, 289-303 (2010).

20. Yu, J. H., Hamari, Z., Han, K. H., Seo, J. A., Reyes-Domínguez, Y., Scazzocchio, C.: Double-joint PCR: A PCR-based molecular tool for gene manipulations in filamentous fungi. Fungal Genet Biol 41, 973-981 (2004).

21. Szewczyk, E., Nayak, T., Oakley, C. E., Edgerton, H., Xiong, Y., Taheri-Talesh, N., Osmani, S. A., Oakley, B. R.: Fusion PCR and gene targeting in Aspergillus nidulans. Nat Protoc 1, 3111-3120 (2006).

22. Greetham, D., Grant, C. M.: Antioxidant activity of the yeast mitochondrial one-Cys peroxiredoxin is dependent on thioredoxin reductase and glutathione in vivo. Mol Cell Biol 29, 3229-3240 (2009).

23. Yin, W. B., Reinke, A. W., Szilágyi, M., Emri, T., Chiang, Y. M., Keating, A. E., Pócsi, I., Wang, C. C., Keller, N. P.: bZIP transcription factors affecting secondary metabolism, sexual development and stress responses in Aspergillus nidulans. Microbiology 159, 77-88 (2013).

24. Emri, T., Pócsi, I., Szentirmai, A.: Analysis of the oxidative stress response of Penicillium chrysogenum to menadione. Free Radic Res 30, 125-132 (1999). 
25. Kim, J. H., Campbell, B. C., Mahoney, N., Chan, K. L., Molyneux, R. J., May, G. S.: Enhancement of fludioxonil fungicidal activity by disrupting cellular glutathione homeostasis with 2, 5-dihydroxybenzoic acid. FEMS Microbiol Lett 270, 284-290 (2007).

26. Amich, J., Dümig, M., O’Keeffe, G., Binder, J., Doyle, S., Beilhack, A., Krappmann, S.: Exploration of sulfur assimilation of Aspergillus fumigatus reveals biosynthesis of sulfurcontaining amino acids as a virulence determinant. Infect Immun 84, 917-929 (2016).

27. Li, Y., Wei, G., Chen, J.: Glutathione: A review on biotechnological production. Appl Microbiol Biotechnol 66, 233-242 (2004).

28. Bachhawat, A. K., Ganguli, D., Kaur, J., Kasturia, N., Thakur, A., Kaur, H., Kumar, A., Yadav, A.: Glutathione production in yeast. In Satyanarayana, T., Kunze, G. (eds.): Yeast Biotechnology: Diversity and Applications, $1^{\text {st }}$ Edition. Springer, Gatersleben, 2009, pp. 259-280.

29. Suzuki, T., Yokoyama, A., Tsuji, T., Ikeshima, E., Nakashima, K., Ikushima, S., Kobayashi, C., Yoshida, S.: Identification and characterization of genes involved in glutathione production in yeast. J Biosci Bioeng 112, 107-113 (2011).

30. Leiter, É., Park, H. S., Kwon, N. J., Han, K. H., Emri, T., Oláh, V., Mészáros, I., Dienes, B., Vincze, J., Csernoch, L., Yu, J.-H., Pócsi, I.: Characterization of the aodA, dnmA, mnSOD and pimA genes in Aspergillus nidulans. Sci Rep 6, 20523 (2016).

31. Zhang, Z. R., Bai, M., Wang, X. Y., Zhou, J. M., Perrett, S.: "Restoration" of glutathione transferase activity by single-site mutation of the yeast prion protein Ure2. J Mol Biol 384, 641-651 (2008).

32. Bourbouloux, A., Shahi, P., Chakladar, A., Delrot, S., Bachhawat, A. K.: Hgt1p, a high affinity glutathione transporter from the yeast Saccharomyces cerevisiae. J Biol Chem $\mathbf{2 7 5}$, 13259-13265 (2000).

33. Wortman, J. R., Gilsenan, J. M., Joardar, V., Deegan, J., Clutterbuck, J., Andersen, M. R., Archer, D., Bencina, M., Braus, G., Coutinho, P., von Döhren, H., Doonan, J., Driessen, A. J., Durek, P., Espeso, E., Fekete, E., Flipphi, M., Estrada, C. G., Geysens, S., Goldman, G., de Groot, P. W., Hansen, K., Harris, S. D., Heinekamp, T., Helmstaedt, K., Henrissat, B., Hofmann, G., Homan, T., Horio, T., Horiuchi, H., James, S., Jones, M., Karaffa, L., Karányi, Z., Kato, M., Keller, N., Kelly, D. E., Kiel, J. A., Kim, J. M., van der Klei, I. J., Klis, F. M., Kovalchuk, A., Krasevec, N., Kubicek, C. P., Liu, B., Maccabe, A., Meyer, V., Mirabito, P., Miskei, M., Mos, M., Mullins, J., Nelson, D. R., Nielsen, J., Oakley, B. R., Osmani, S. A., Pakula, T., Paszewski, A., Paulsen, I., Pilsyk, S., Pócsi, I., Punt, P. J., Ram, A. F., Ren, Q., Robellet, X., Robson, G., Seiboth, B., van Solingen, P., Specht, T., Sun, J., Taheri-Talesh, N., Takeshita, N., Ussery, D., vanKuyk, P. A., Visser, H., van de Vondervoort, P. J., de Vries, R. P., Walton, J., Xiang, X., Xiong, Y., Zeng, A. P., Brandt, B. W., Cornell, M. J., van den Hondel, C. A., Visser, J., Oliver, S. G., Turner, G.: The 2008 update of the Aspergillus nidulans genome annotation: A community effort. Fungal Genet Biol 46, S2-S13 (2009).

34. Sato, I., Shimatani, K., Fujita, K., Abe, T., Shimizu, M., Fujii, T., Hoshino, T., Takaya, N.: Glutathione reductase/glutathione is responsible for cytotoxic elemental sulfur tolerance via polysulfide shuttle in fungi. J Biol Chem 286, 20283-20291 (2011).

35. Fraser, J. A., Davis, M. A., Hynes, M. J.: A gene from Aspergillus nidulans with similarity to URE2 of Saccharomyces cerevisiae encodes a glutathione S-transferase which contributes to heavy metal and xenobiotic resistance. Appl Environ Microbiol 68, 2802-2808 (2002). 
36. Spitzmüller, Z., Hajdú, M., Pócsi, I., Emri, T.: Degradation of glutathione in Aspergillus nidulans - Short communication. Acta Biol Hung 66, 242-245 (2015).

37. Thön, M., Al Abdallah, Q., Hortschansky, P., Scharf, D. H., Eisendle, M., Haas, H., Brakhage, A. A.: The CCAAT-binding complex coordinates the oxidative stress response in eukaryotes. Nucleic Acids Res 38, 1098-1113 (2010).

38. Pusztahelyi, T., Klement, É., Szajli, E., Klem, J., Miskei, M., Karányi, Z., Emri, T., Kovács, S., Orosz, G., Kovács, K. L., Medzihradszky, K. F., Prade, R. A., Pócsi, I.: Comparison of transcriptional and translational changes caused by long-term menadione exposure in Aspergillus nidulans. Fungal Genet Biol 48, 92-103 (2011).

39. Navarro, R. E., Stringer, M. A., Hansberg, W., Timberlake, W. E., Aguirre, J.: catA, a new Aspergillus nidulans gene encoding a developmentally regulated catalase. Curr Genet 29, 352-359 (1996).

40. Ruijter, G. J., Bax, M., Patel, H., Flitter, S. J., van de Vondervoort, P. J., de Vries, R. P., vanKuyk, P. A., Visser, J.: Mannitol is required for stress tolerance in Aspergillus niger conidiospores. Eukaryot Cell 2, 690-698 (2003).

41. Thön, M., Al-Abdallah, Q., Hortschansky, P., Brakhage, A. A.: The thioredoxin system of the filamentous fungus Aspergillus nidulans: Impact on development and oxidative stress response. J Biol Chem 282, 27259-27269 (2007).

42. Ni, M., Yu, J. H.: A novel regulator couples sporogenesis and trehalose biogenesis in Aspergillus nidulans. PLoS One 2, e970 (2007).

43. Slesiona, S., Gressler, M., Mihlan, M., Zaehle, C., Schaller, M., Barz, D., Hube, B., Jacobsen, I. D., Brock, M.: Persistence versus escape: Aspergillus terreus and Aspergillus fumigatus employ different strategies during interactions with macrophages. PLoS One 7, e31223 (2012).

44. Hagiwara, D., Suzuki, S., Kamei, K., Gonoi, T., Kawamoto, S.: The role of AtfA and HOG MAPK pathway in stress tolerance in conidia of Aspergillus fumigatus. Fungal Genet Biol 73, 138-149 (2014).

45. Hagiwara, D., Takahashi, H., Kusuya, Y., Kawamoto, S., Kamei, K., Gonoi, T.: Comparative transcriptome analysis revealing dormant conidia and germination associated genes in Aspergillus species: an essential role for AtfA in conidial dormancy. BMC Genomics 17, 358 (2016).

46. Grant, C. M., MacIver, F. H., Dawes, I. W.: Glutathione is an essential metabolite required for resistance to oxidative stress in the yeast Saccharomyces cerevisiae. Curr Genet 29, 511-515 (1996).

47. Fekete, A., Emri, T., Gyetvai, A., Gazdag, Z., Pesti, M., Varga, Z., Balla, J., Cserháti, C., Emődy, L., Gergely, L., Pócsi, I.: Development of oxidative stress tolerance resulted in reduced ability to undergo morphologic transitions and decreased pathogenicity in a $t$-butylhydroperoxide-tolerant mutant of Candida albicans. FEMS Yeast Res 7, 834-847 (2007).

48. Fekete, A., Pócsi, I., Emri, T., Gyetvai, A., Gazdag, Z., Pesti, M., Karányi, Z., Majoros, L., Gergely, L., Pócsi, I.: Physiological and morphological characterization of tertbutylhydroperoxide tolerant Candida albicans mutants. J Basic Microbiol 48, 480-487 (2008).

49. Jakab, Á., Antal, K., Kiss, Á., Emri, T., Pócsi, I.: Increased oxidative stress tolerance results in general stress tolerance in Candida albicans independently of stress-elicited morphological transitions. Folia Microbiol (Praha) 59, 333-340 (2014). 